\title{
Self-rated treatment outcomes in medical rehabilitation among German and non- German nationals residing in Germany: an exploratory cross-sectional study
}

\author{
P. Brzoska ${ }^{1,2^{*}}$, O. Sauzet $^{1}$, Y. Yilmaz-Aslan ${ }^{1,3}$, T. Widera $^{4}$ and O. Razum ${ }^{1}$
}

\begin{abstract}
Background: In many European countries, foreign nationals experience, on average, less favorable treatment outcomes in rehabilitative care than the respective majority population. In Germany, this for example is reflected in a lower occupational performance and a higher risk of disability retirement after rehabilitation as analyses of routine data show. However, little is known about the perspective of health care users. The aim of the present study was to compare self-rated treatment outcomes between German and non-German nationals undergoing in-patient medical rehabilitation in Germany.

Methods: We analyzed data from a cross-sectional representative rehabilitation patient survey of 239,811 patients from 642 clinics in Germany who completed about 3 weeks of in-patient rehabilitative treatment. The self-rating of the treatment outcome was based on a dichotomized Likert scale consisting of three items. A multilevel logistic regression analysis adjusted for various demographic, socio-economic, health and other covariates was conducted to examine differences in the self-rated treatment outcome between German and non-German nationals.

Results: Of the 239,811 respondents $0.9 \%$ were nationals from Turkey, $0.8 \%$ had a nationality from a former Yugoslavian country, $0.9 \%$ held a nationality from the South European countries Portugal, Spain, Italy or Greece and $1.9 \%$ were nationals from other countries. Non-German nationals reported a less favorable self-rated outcome than Germans. Adjusted odds ratios [OR] for reporting a less favorable treatment outcome were 1.24 (95\%-confidence interval [95 \%-Cl]: 1.12-1.37) for nationals from the South European countries Portugal/Spain/Italy/Greece, 1.62 (95 \%-Cl: 1.45-1.80) for Turkish nationals and 1.68 (95 \%-Cl: 1.52-1.85) for nationals from Former Yugoslavia.

Conclusions: Knowledge on health outcomes from the patients' point of view is important for the provision of patientcentered health care. Our study showed that non-German nationals report less favorable outcomes of rehabilitative care than Germans. This may be due to cultural and religious needs not sufficiently addressed by health care providers. In order to improve rehabilitative care for non-German nationals, rehabilitative services must become sensitive to the needs of this population group. Diversity management can contribute to this process.
\end{abstract}

Keywords: Migrants, Inequity, Rehabilitation, Effectiveness, Health services research

\footnotetext{
* Correspondence: patrick.brzoska@uni-bielefeld.de

'Department of Epidemiology \& International Public Health, Bielefeld

University, School of Public Health, Bielefeld, Germany

${ }^{2}$ Chemnitz University of Technology, Faculty of Behavioral and Social

Sciences, Institute of Sociology, Chemnitz, Germany

Full list of author information is available at the end of the article
} 


\section{Background}

Foreign nationals comprise increasingly large proportions of the populations in many European countries. They differ in some health-related aspects from the majority populations of the countries they reside in. This comprises patterns of disease, health outcomes and health behavior $[1,2]$. In Germany, $8.6 \%$ of the total population (equaling about 6.8 million individuals) has a non-German citizenship according to the microcensus, a representative household survey in Germany [3]. Nationals from Turkey, Former Yugoslavia and the South European countries Portugal, Spain, Italy and Greece constitute about half of the population of nonGerman nationals residing in Germany. Many of these individuals or their parents were recruited as labor migrants between the 1950s and the 1970s and then settled in the country followed by their families [3].

Data on the health of migrants is limited [4]. The few available studies show a multifaceted picture. On the one hand, non-Germans have some health advantages over the majority population, e.g., with respect to a lower incidence of certain types of cancer. On the other hand, they have, on average, a higher prevalence of work-related disability and of chronic disorders such as diabetes mellitus type 2 . They also experience higher rates of occupational accidents and occupational diseases $[2,5]$. There is evidence that these differences are due to various environmental and social factors which migrants are exposed to in different phases of their life, comprising the time before, during and after the migration process. Negative exposures in the host country include, amongst others, poor working conditions, a lower socioeconomic status and a poor language proficiency $[2,6]$.

The German health care system is ethically, legally and socially responsible for providing adequate health services to the entire population of their countries-including residents with a foreign nationality [4]. Rehabilitative services are of particular relevance for non-German nationals considering their overall higher burden of chronic diseases and higher rates of work-related disability as outlined above. As a measure of tertiary prevention, rehabilitation can mitigate the consequences of acute and chronic diseases and can restore a deteriorated health status [7].

In Germany, rehabilitative care is covered by different institutions of the health care system. The German Statutory Pension Insurance Scheme covers rehabilitative treatments for individuals in working age as well as for patients with cancer. Together, they make up for about two-thirds of all cases seeking rehabilitative care in Germany [8]. The rehabilitative services as covered by the German Statutory Pension Insurance Scheme are usually provided as 3-weeks in-patient programs conducted in specialized clinics [9]. Rehabilitative services for people in retirement age with diseases other than cancer are covered by other social security institutions, mainly by the Statutory Health Insurance [8].

Only few studies have been carried out on the effectiveness of rehabilitation in Germany. Many of them support the effectiveness of rehabilitative treatments but are usually restricted to particular clinical conditions [10]. The scarce evidence is critically appraised by the Advisory Council on the Assessment of Developments in the Health Care System in its recent report and reveals future research need in this field [10].

Non-Germans and Germans have equal rights to use rehabilitation free of charge as part of their social insurance (the situation is different for asylum seekers who are initially only entitled to receive emergency care for acute health problems free of charge [2]). However, studies based on routine and survey data show that non-Germans utilize rehabilitation less often than Germans [11-13]. They also experience, on average, less favorable treatment outcomes, which is reflected in a lower occupational performance and a higher risk of disability retirement after rehabilitation [11, 13-15]. This is particularly true for individuals with a nationality from Turkey and Former Yugoslavia. Differences in the utilization and outcomes of rehabilitation between German and non-German nationals cannot be explained by differences in health status or demographic and socio-economic factors [11, 13-15]. Similar results were reported from other countries [16-19]. For example, Sloots et al. observed higher rates of drop-out from rehabilitation among Turkish and Moroccan migrants as compared to the Dutch majority population in the Netherlands [16, 17].

One important limitation of previous investigations into the rehabilitative care of migrants in Germany is that little is known about the perspective of health care users. Subjective treatment effects perceived by patients such as quality of life and self-rated performance, however, are important indicators of health care quality and essential patient-reported outcomes [20, 21]. They predict objective treatment outcomes such as return to work and prevention of early retirement [22-24] and are also strongly correlated with doctors' evaluation of clinical outcomes [25]. Considering patients' point of view, for example by evaluating self-rated treatment outcomes, is immanent to the provision of patient-centered health care and to the achievement of outcomes that are relevant to patients [26, 27]. In Germany, several investigations in the rehabilitation setting have shown that self-rated treatment outcomes are associated with demographic and socio-economic factors, and that they may vary between patients with different clinical conditions [28-34].

Little is known about the self-rated treatment outcomes in rehabilitative services among migrants. Possible difference in these outcomes between migrants and 
non-migrants after adjusting for common social determinants could be indicative of health disparities and could contribute to improving rehabilitative care for this population group. Gruner et al. studied a small sample of migrants and non-migrants in Germany who underwent in-patient medical rehabilitation for psychosomatic conditions [35]. They showed that migrants tended to have a less favorable self-rated work-related performance after rehabilitation than non-migrants. The study, however, was conducted in only one clinic in South Germany. Because of its exploratory character, differences between migrants and non-migrants in terms of health status as well as demographic and socio-economic characteristics could not be adjusted for. Hence, it remains unclear whether differences in the self-rated outcome merely reflect the influence of confounding variables or point towards inequities in health care between both populations.

The aim of the present study was to address these limitations by means of a large sample which allows to compare self-rated treatment outcomes between Germans and non-Germans undergoing in-patient medical rehabilitation in all regions of Germany. Furthermore, the sample allowed us to take different covariates into account which might confound the relationship between nationality and outcomes of rehabilitative care.

\section{Methods}

\section{Data}

We analyzed data from a cross-sectional representative rehabilitation patient survey implemented by the German Statutory Pension Insurance Scheme ('Deutsche Rentenversicherung') among individuals who completed about 3 weeks of in-patient rehabilitative care granted by this institution. Rehabilitative treatments for people in retirement age with diseases other than cancer are covered by other social security institutions such as the Statutory Health Insurance are not included in our analysis.

The patient survey is part of an external quality assurance program implemented by the German Statutory Pension Insurance Scheme for its rehabilitation clinics following legal requirement as defined by the German Social Code VI and IX. From each rehabilitation facility, 20 patients who completed medical rehabilitation are randomly selected on a monthly basis and approached at home 8-12 weeks after their treatment by means of a postal self-administered questionnaire. They provide a written informed consent regarding participation in the survey. The survey is conducted in German language. The average response rate per year is $55 \%$ [36]. The collection and use of the data for research purposes (secondary data analysis) is in accord with the legal requirements for routinely assessed data as defined by the German Social Code X. Also, the data are fully anonymized.
Therefore, no additional ethical approval for the current analysis was necessary [37].

For the present study, we drew on data from 274,513 individuals diagnosed with somatic conditions who underwent in-patient medical rehabilitation in one of 624 rehabilitation clinics during 2007-2011.

\section{Measures}

As part of the rehabilitation patient survey, patients are asked to assess the degree to which the rehabilitative service they utilized improved (a) their health status, (b) their occupational performance and (c) their performance in everyday life and leisure-time activities. This can be considered a relative assessment because it is based on a subjective comparison of the perceived health status before and after utilization of the service. The assessment of each of these three items is conducted on a five-point Likert scale ( $1=$ "considerably deteriorated", $2=$ "slightly deteriorated", 3="unchanged", 4 = "slightly improved", 5="considerably improved"). A correlation analysis carried out for the present study showed that the three items were highly correlated ranging from $r=0.7-$ 0.8 (Spearman rho). A mean score based on the responses to the three items was calculated and dichotomized $(<4$ "perceived health/performance deteriorated or unchanged" vs. $\geq 4$ "perceived health/performance improved").

We were able to compare Germans with four groups of non-German nationals: Turkey, Former Yugoslavia, Portugal/Spain/Italy/Greece and 'other', similar to previous studies based on routine data of the German Statutory Pension Insurance Scheme [11, 14]. Information on nationality included in the routine data of the German Statutory Pension Insurance Scheme is obtained from official registry data [37].

In line with previous research we also controlled for relevant covariates which have been shown to be associated with treatment outcomes [28-34]. These covariates are based on a covariate model suggested for analyses of routine data of the German Statutory Pension Insurance Scheme [33]. These covariates were age (in years), sex, marital status (single/divorced/widowed, married), education (low, intermediate, high, other/unknown) occupational position (skilled labor, semi-skilled/unskilled labor, trainee/unemployed), the type of somatic diagnosis on admission to rehabilitation (diseases of the skeletal system, neoplasms, diseases of the circulatory system, other), the time absent from work due to illness in the last 12 months before rehabilitation (0 months, $<3$ months, 3 to $<6$ months, $\geq 6$ months, not employed) and the perceived occupational performance before rehabilitation (low, moderate/high, not mentioned). The latter two variables were considered as proxies for disease severity before rehabilitation. Furthermore, following procedures in other studies [33, 38-40], information 
on whether respondents received assistance in completing the self-administered questionnaire was considered as a proxy for German language proficiency, for comprehensibility of the questionnaire and for other factors that limited patients in filling in the questionnaire on their own. Finally, the overall satisfaction of the patient with the care received (low/moderate, high) and type of rehabilitation (rehabilitation directly following a hospital stay vs. [optional] rehabilitation provided independently of a prior hospital stay) were accounted for. Since early retirement in Germany cannot be granted for individuals unless their potential for rehabilitation is fully exhausted, seeking optional rehabilitative treatment may be indicative of a high motivation for early retirement and a low motivation for a successful completion of rehabilitation [41]. All variables had less than $3 \%$ of missing values.

\section{Statistical analysis}

Tabulation stratified by nationality was used for sample description. Given the large sample size no significance tests were conducted for this purpose. Multilevel logistic regression models were used to analyze the relationship between nationality (independent variable) and the perceived treatment outcome (dependent variable). To adjust for covariates, multivariable models were computed. The multilevel analysis was performed to account for the clustering of respondents within the 642 rehabilitation clinics. The intraclass correlation coefficient (ICC) was calculated following the multivariable analysis to estimate the proportion of the total variance in the perceived treatment outcome that is due to differences between clinics rather than differences between individuals [42].

For all models, odds ratios (OR) and $95 \%$ confidence intervals $(95 \%-\mathrm{CI})$ were calculated. All analyses were performed using the software Stata, version 12 [43].

\section{Results}

Data for 239,811 individuals was available with complete information for all variables. Of these, $0.9 \%$ $(n=2155)$ were nationals from Turkey, $0.8 \%(n=2267)$ had a nationality from a former Yugoslavian country, $0.9 \%(n=2061)$ held a nationality from the South European countries Portugal, Spain, Italy or Greece and $1.9 \%(n=4846)$ were nationals from other countries. In total, $4.5 \%(n=11,329)$ of all respondents participating in the survey had a non-German nationality.

Table 1 shows the characteristics of the study sample stratified by nationality (group). German and non-German nationals differed in their demographic and socio-economic characteristics. Amongst others, this is reflected in a higher proportion of non-German respondents who were male, who only had a low school education and who worked in semi-skilled/unskilled occupational positions. Differences also become evident with respect to underlying diseases conditions, with larger proportions of non-Germans compared to Germans, for instance, undergoing rehabilitation because of diseases of the skeletal system. Furthermore, the proportions of patients who reported a moderate/high selfrated performance before rehabilitation was lower among non-Germans than among Germans. The same applied to the proportion of individuals who were highly satisfied with the rehabilitative care received.

As is further shown in Table 1, the percentage of respondents who reported that their health/performance improved through their rehabilitative treatment varied between the different groups of non-German nationals. While $54.2 \%$ of all Germans reported an improvement of their health/performance following rehabilitation, the respective proportions were considerably lower for nonGerman nationals, being $28.1 \%$ for Turkish nationals, 34.5 \% for Former Yugoslavian nationals and 38.0 \% for nationals from Portugal, Spain, Italy or Greece.

Around $5 \%$ of the total variance in the perceived treatment outcome can be explained by the 642 rehabilitation clinics $(\mathrm{ICC}=0.046)$, warranting a multilevel approach to represent heterogeneity in the data. The results of the multilevel regression model with deteriorated or unchanged health/performance as the dependent variable adjusted for covariates are displayed in Table 2. It becomes evident that the differences in the perceived treatment outcome between the nationality strata still exist even after controlling for demographic and socioeconomic characteristics as well as health and other covariates. As compared to German nationals, Turkish and Former Yugoslavian nationals had a 62 and $68 \%$ higher chance, respectively, of an unfavorable perceived treatment outcome $(\mathrm{OR}=1.62$; $95 \%$-CI: $1.45-1.80$ and $\mathrm{OR}=1.68$; $95 \%$-CI: $1.52-1.85$, respectively). The respective chance among nationals from Portugal, Spain, Italy or Greece was $24 \%$ higher $(\mathrm{OR}=1.24 ; 95 \%$-CI: $1.12-1.37)$.

Aside from non-German nationality, a low or intermediate educational status and occupational position, a longer time absent from work in the last 12 months before rehabilitation, a low self-rated performance before rehabilitation and a low/moderate satisfaction with the rehabilitation service, amongst others, were associated with a higher chance of a poor perceived outcome of rehabilitative care.

\section{Discussion}

In many European countries, foreign nationals benefit less from health care services than the respective majority populations. In Germany, this is particularly reflected in (tertiary) preventive services such as rehabilitation. Considering the overall higher burden of chronic diseases and impairment among non-German nationals, rehabilitative services are of particular importance. Knowledge on selfrated treatment outcomes can help to improve health care 
Table 1 Description of the study sample stratified by nationality (participants of the rehabilitation client survey of the German Statutory Pension Insurance Scheme conducted between 2007 and 2011, n=251,140)

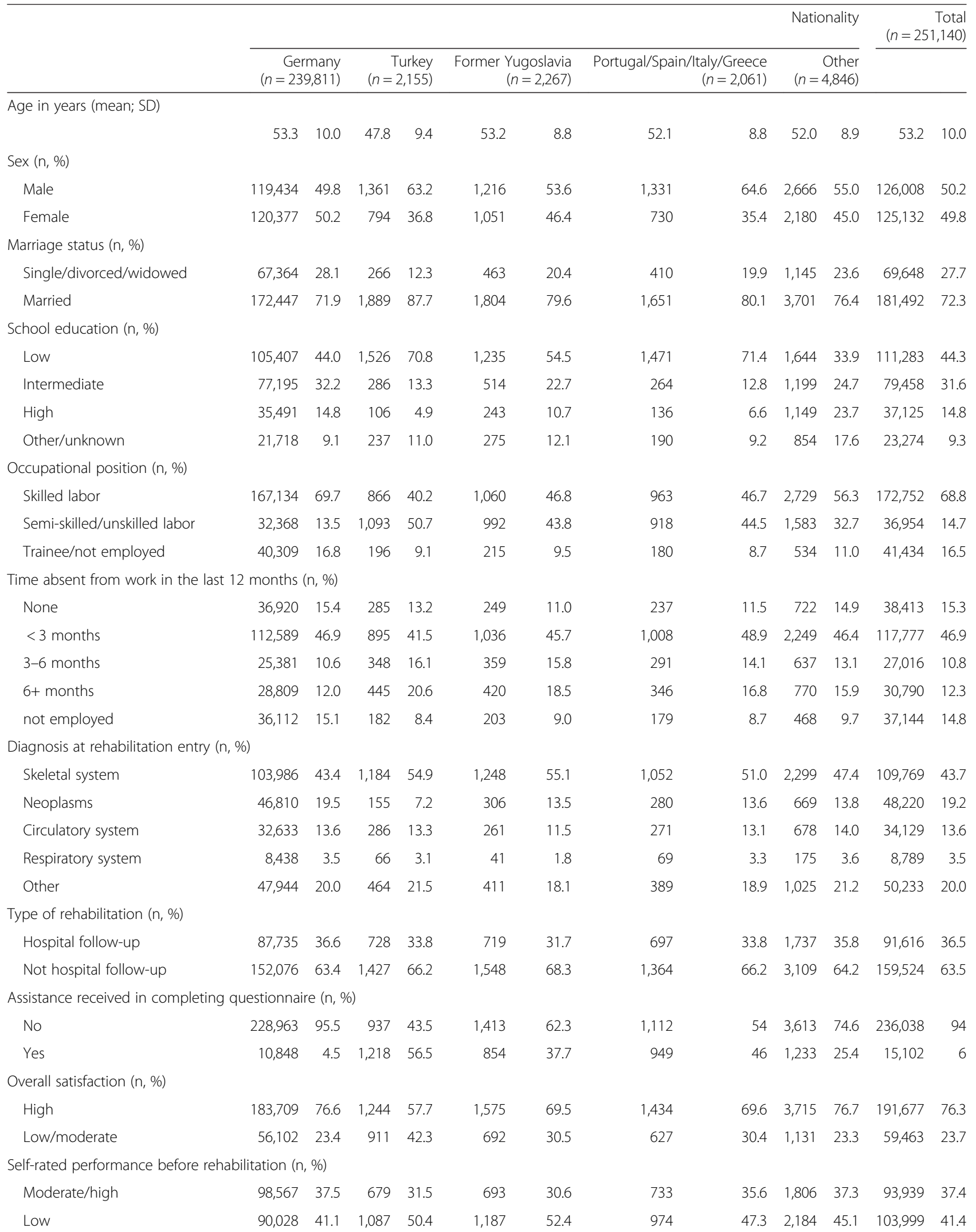


Table 1 Description of the study sample stratified by nationality (participants of the rehabilitation client survey of the German Statutory Pension Insurance Scheme conducted between 2007 and 2011, $n=251,140$ ) (Continued)

\begin{tabular}{|c|c|c|c|c|c|c|c|c|c|c|c|c|}
\hline Not stated & 51,216 & 21.4 & 389 & 18.1 & 387 & 17.1 & 354 & 17.2 & 856 & 17.7 & 53,202 & 21.2 \\
\hline \multicolumn{13}{|l|}{ Subjective treatment outcome $(n, \%)$} \\
\hline Health/performance improved & 129,861 & 54.2 & 605 & 28.1 & 781 & 34.5 & 784 & 38.0 & 2,401 & 49.5 & 134,432 & 53.5 \\
\hline $\begin{array}{l}\text { Health/performance deteriorated } \\
\text { or unchanged }\end{array}$ & 109,950 & 45.8 & 1,550 & 71.9 & 1,486 & 65.5 & 1,277 & 62.0 & 2,445 & 50.5 & 116,708 & 46.5 \\
\hline
\end{tabular}

Note. SD standard deviation

for this population group and to reduce existing health disparities.

The aim of the present investigation was to compare self-rated treatment outcomes in rehabilitation between German and non-German nationals residing in Germany. It shows that non-German nationals report a less favorable outcome of their rehabilitative treatment than Germans. A previous study, which showed that migrants undergoing psychosomatic rehabilitation have a poorer self-rated work performance after the treatment than nonmigrants, was limited in two important respects. First, it was based on a small sample from one clinic in Germany. Second, it was exploratory and was not able to take differences between migrants and non-migrants in terms of health status as well as demographic and socio-economic characteristics into account [35]. By means of representative data for Germany covering all somatic rehabilitations through the years 2007-2011, we add to these findings by illustrating that differences in the self-rated treatment outcomes cannot be explained by demographic and socioeconomic factors or a different disease profile and health status before rehabilitation alone. Since we adjusted for the satisfaction with health care, it is also unlikely that poorer perceived health outcomes are merely a reflection of dissatisfaction with treatment which has been observed among migrants $[44,45]$. Our results are also in accord with previous research. It showed that the association between non-German nationality and objective outcomes of rehabilitative care such as the occupational performance as evaluated by health professionals $[11,15]$ or the risk of disability retirement after rehabilitation [14] cannot be explained by a different distribution of demographic, socio-economic and health variables between the two population groups. These studies, as does the present investigation, show that patients of Turkish and Former Yugoslavian origin tended to be more vulnerable to a poor treatment outcome than patients originating from the South-European countries Portugal, Spain, Italy or Greece.

One possible explanation for our findings may be various barriers that migrants experience in the health care system. Several qualitative investigations in somatic health care in general $[46,47]$ as well as rehabilitation in particular $[48,49]$ have highlighted different challenges and obstacles migrants face in the German health care setting. They interfere with an adequate provision of care and may result in reduced health care quality. These challenges result from a low German language proficiency which is still prevalent among many, particularly older, migrants residing in Germany [50]. In rehabilitation this can lead to communication problems between patients and health care providers by making it difficult for health professionals to obtain the medical history of patients or to instruct patients about therapies and necessary exercises. A low proficiency in the language of the host country may also negatively affect health literacy [51]. Health literacy is an important determinant of informed decision making in health care [52] and has been shown to be limited among migrant populations residing in Germany [53, 54]. For the present study it must be considered, however, that the rehabilitation patient survey is conducted in German language which is why only patients with a sufficient amount of German language proficiency or who receive assistance in completing the questionnaire take part in the survey. Since we adjusted for help received in the completion of the questionnaire, low language proficiency cannot fully explain the findings of our investigation. Aside from problems due to poor language proficiency also cultural and religious needs, expectations and preferences (e.g., with respect to illness perceptions, the way symptoms and illness are expressed, coping with disease or cultural and social taboos), which are not sufficiently accounted for by health care institutions may affect the patient-provider relationship negatively when inadequately addressed in the health care process. Similar to low German language proficiency they can lead to conflicts between health care users and providers and may reduce health care quality $[19,20]$.

The association between an unfavorable perceived outcome of rehabilitation and the covariates which we took into account in our multivariable analysis to adjust for potential confounding are mostly in line with those identified in other studies on treatment outcomes in rehabilitation [11, 14, 15, 55-57]. In our study, some of the covariates had a larger effect size than nationality. Still, despite adjusting for these variables, considerable differences between the nationality strata existed. 
Table 2 Results of the multivariable logistic regression model with deteriorated or unchanged health/performance as the dependent variable. Odds ratios (OR) and $95 \%$ confidence intervals [95\%-Cl] (participants of the rehabilitation client survey of the German Statutory Pension Insurance Scheme conducted between 2007 and 2011, $n=251,140$ )

\begin{tabular}{ll}
\hline & OR \\
\hline Nationaty
\end{tabular}

Nationality

Germany (Reference)
Portugal/Spain/Italy/Greece
Former Yugoslavia
Turkey
Other

Age in years

Sex

Male (Reference)

Female

Marriage status

Single/divorced/widowed (Reference)

Married

School education

High (Reference)

Intermediate

Low

Other/unknown

Occupational position

Skilled labor (Reference)

Semi-skilled/unskilled labor

Trainee/not employed

Time absent from work in the last 12 months

None (Reference)

$<3$ months

3-6 months

$6+$ months

not employed

Diagnosis at rehabilitation entry

Skeletal system (Reference)

Neoplasms

Circulatory system

Respiratory system

Other

Type of rehabilitation

Hospital follow-up (Reference)

Not hospital follow-up

Assistance received in completing questionnaire No (Reference)

Yes

$(0.88 ; 0.92)$ $(0.95 ; 1.01)$ $(1.28 ; 1.37)$ $(1.94 ; 2.08)$ $(1.01 ; 1.14)$

$(0.90 ; 0.99)$

$(1.07 ; 1.18)$

$(0.88 ; 1.03)$

$(1.01 ; 1.08)$
Table 2 Results of the multivariable logistic regression model with deteriorated or unchanged health/performance as the dependent variable. Odds ratios (OR) and $95 \%$ confidence intervals [95\%-Cl] (participants of the rehabilitation client survey of the German Statutory Pension Insurance Scheme conducted between 2007 and 2011, $n=251,140$ ) (Continued)

\begin{tabular}{l}
\hline $\begin{array}{l}\text { Overall satisfaction } \\
\text { High (Reference) }\end{array}$ \\
Low/moderate \\
Self-rated performance before rehabilitation \\
$\quad$ Mediocre/high (Reference) \\
Low \\
Not stated \\
\hline Note. OR odds ratio, $95 \%$-Cl $95 \%$ confidence interval
\end{tabular}

\section{Strengths and limitation}

A strength of our study is the use of data from a representative rehabilitation patient survey which is routinely conducted by a large social security institution in Germany covering the majority of rehabilitative treatments in the country [8]. Given different measures of quality control implemented by this institution, the quality of the data can be considered high [37]. A previous investigation into the perceived treatment outcomes in rehabilitation [35] was limited by its narrow focus on one clinic and a small sample size which only allowed a descriptive analysis. By means of a representative survey we were able to give an account of rehabilitative treatments by the German Statutory Pension Insurance Scheme provided in the entire country and to control for different covariates potentially obscuring the relationship between nationality and outcomes of rehabilitative care [11].

Our study also has some limitations. The rehabilitation patient survey is conducted in German language. Although we tried to control for a possible bias resulting from low German language proficiency by adjusting the multivariable model for assistance that survey participants received when completing the questionnaire, it is likely that some patients with little German language proficiency did not take part in the survey (information on nonresponders are not available). This may have introduced a selection bias, which in turn may explain why the proportion of non-German (particularly Turkish) nationals in the total sample of respondents was lower than could have been expected based on routine data on all completed rehabilitations covered by the German Statutory Pension Insurance Scheme. This data shows that about 1.4, 1.1 and $1.0 \%$ of all patients who completed a rehabilitative treatment in the years 2007-2011 had a nationality from Turkey, Former Yugoslavia and Portugal/Spain/Italy/ Greece, respectively. Given proportions of $0.8,0.9$ and $0.9 \%$ of nationals from Turkey, Former Yugoslavia and 
Portugal/Spain/Italy/Greece, respectively, who took part in the patient survey, it becomes evident that the difference between the expected and observed proportion of non-German individuals in our sample is particularly pronounced for Turkish patients. Proportions for nationals from Former Yugoslavia and Portugal/Spain/Italy/Greece only differ slightly. A reason for this could be that Turkish migrants in Germany are particularly prone to low German language proficiency [58]. Based on studies which compared rehabilitative outcomes between German and non-German nationals by means of routine data on all completed rehabilitations covered by the German Statutory Pension Insurance Scheme, it can be assumed that the differences between German nationals and nonGermans in our study would be even more pronounced if a multilingual survey would have been used. Since, to our knowledge, no studies have been conducted on differences in rehabilitative outcomes between individuals with poor and good German language proficiency which would allow to quantify a potential selection bias, this issue should be subject of future research.

Because of the limitations inherent to the data set (and to many similar routine data sets in Germany [59]) we were only able to define migrants through a non-German nationality. Since other information which would allow to assess migration status more thoroughly such as the country of origin or the birth place of parents are missing, only a part of the population of migrants could be studied in our investigation. We consider the resulting bias to be small because other studies in the field that were able to also consider migrants of German nationality (for example those who immigrated to Germany and acquired German citizenship) did not identify relevant differences between this population and non-Germans in terms of outcomes of rehabilitative care $[15,60]$.

Patient surveys may be prone to a recall bias, particularly when patients are asked to evaluate a clinic stay that took place several months ago [61]. In the present case, we do not consider this to have an impact on our results as the main focus of our investigation is the effectiveness of rehabilitation as it is rated by patients already 6 weeks after rehabilitation and with respect to activities at work and everyday life. In addition, there is no reason why recall bias should differ between the population groups. Our data, though, only allows a cross-sectional analysis with patients evaluating the outcome of rehabilitation $8-12$ weeks after discharge. It is possible that the self-rated effectiveness of rehabilitation as well as differences between the population groups change over time [61].

We used information on whether respondents received assistance in completing the self-administered questionnaire as a proxy measure for factors limiting patients in filling in the survey instrument on their own. This procedure is in line with other studies [38-40] and aims to control for a potential bias arising from the assisted completion. However, no further information on the type of limiting factors are available, which may, amongst others, include poor language proficiency but also the inability to read and write because of impairment.

As mentioned previously, our study only covers somatic in-patient rehabilitations provided by the German Statutory Pension Insurance Scheme. Further research needs to investigate whether our results can also be extended to out-patient rehabilitative services, to services targeting mental conditions and to services provided by other social security institutions in Germany.

Finally, our study is based on cross-sectional data. However, we used a type of outcome measure which allows an indirect adjustment for baseline health differences. Thus, we consider the difference in the self-rated treatment outcome that we identified between the population groups very informative and indicative of health disparities. Still, more experimental studies on the effectiveness of rehabilitation in Germany are urgently needed [10].

\section{Conclusions}

Knowledge on health outcomes from the patients' point of view is important for health care providers so they can provide services to users which meet their subjective and objective needs. Our study showed that nonGerman nationals report less favorable outcomes of rehabilitative care. This may be due to cultural and religious needs not sufficiently addressed by health care providers. Different strategies are available to address cultural and religious heterogeneity in health care and to provide services catering for the diversity of patients [62-64]. They comprise cross-cultural trainings for health providers as well as the employment of health navigators and interpreters. Another more holistic approach is diversity management which not only allows to take into account the needs of migrants but which also acknowledges that expectations and preferences in health care do not only vary with migration status or culture but also with other diversity characteristics such as sex, age and socioeconomic position [65]. Diversity management comprises different measures. They include, for example, drafting diversity-sensitive mission statements, identifying strengths and limitations related to the diversity of patients and staff, promoting selfreflection and an open attitude, as well using pictographic information systems in health facilities to allow an easy way of orientation for patients with limited reading capabilities [66-68].

Implementing diversity management in health care institutions can improve health care for the entire population as has been shown by evaluation studies $[69,70]$. As stated by the Advisory Council on the Assessment of 
Developments in the Health Care System for Germany, more studies need to be conducted on the effectiveness of rehabilitation in Germany [10]. While observational studies such as the present one provide valuable insights into determinants of favorable treatment outcomes, also experimental studies employing a longitudinal approach need to be implemented. Since these studies usually require substantial resources, sufficient funding by stakeholders in the German system of rehabilitation must be provided.

\section{Abbreviations}

OR: odds ratio; 95 \%-Cl: 95 \%-confidence interval; ICC: Intraclass correlation coefficient.

\section{Competing interests}

The authors declare that they have no competing interests.

\section{Authors' contributions}

PB developed the concept and design of the study, performed the statistical analysis, interpreted the findings and drafted the manuscript. OS assisted in the statistical modeling of the data and in writing the manuscript. YYA and TW helped to interpret the findings. OR helped with the study design and data interpretation and critically revised the manuscript. All authors read and approved the final manuscript.

\section{Acknowledgements}

The study was funded by a grant from the Association for Rehabilitation Research in North Rhine-Westphalia (Gesellschaft für Rehabilitationswissenschaften Nordrhein- Westfalen e.V.) whose support we acknowledge. We also acknowledge support of the publication fee by the German Research Foundation (Deutsche Forschungsgemeinschaft) and the Open Access Publication Funds of Bielefeld University.

\section{Author details}

'Department of Epidemiology \& International Public Health, Bielefeld University, School of Public Health, Bielefeld, Germany. ${ }^{2}$ Chemnitz University of Technology, Faculty of Behavioral and Social Sciences, Institute of Sociology, Chemnitz, Germany. ${ }^{3}$ Department of Public Health, Giresun University, Faculty of Medicine, Giresun, Turkey. ${ }^{4}$ German Statutory Pension Insurance Scheme, Social Medicine and Rehabilitation, Section Rehabilitation Research (Deutsche Rentenversicherung Bund, Geschäftsbereich Sozialmedizin und Rehabilitation, Bereich Reha-Wissenschaften), Berlin, Germany.

\section{Received: 27 March 2015 Accepted: 16 March 2016}

\section{Published online: 28 March 2016}

\section{References}

1. Solé-Auró A, Crimmins EM. Health of immigrants in European countries. Int Migr Rev. 2008;42:861-76.

2. Razum O, Zeeb H, Meesmann U, Schenk L, Bredehorst M, Brzoska P, Dercks T, Glodny S, Menkhaus B, Salman R, et al. Migration und Gesundheit. Berlin: Robert Koch-Institut; 2008.

3. Statistisches Bundesamt. Bevölkerung und Erwerbstätigkeit. Bevölkerung mit Migrationshintergrund. Ergebnisse des Mikrozensus 2010 (Fachserie 1 Reihe 2.2). Wiesbaden: Statistisches Bundesamt; 2011.

4. Brzoska P, Ellert U, Kimil A, Razum O, Saß A-C, Salman R, Zeeb H. Reviewing the topic of migration and health as a new national health target for Germany. Int J Public Health. 2015;60:13-20.

5. Brzoska P, Voigtländer S, Spallek J, Razum O. Arbeitsunfälle, Berufskrankheiten und Erwerbsminderung bei Menschen mit Migrationshintergrund. In: Schott T, Razum O, editors. Migration und gesundheitliche Ungleichheit in der Rehabilitation. Weinheim: Beltz Juventa; 2013. p. 49-61.

6. Spallek J, Zeeb H, Razum O. What do we have to know from migrants' past exposures to understand their health status? A life course approach. Emerg Themes Epidemiol. 2011;8:6.
7. World Health Organization. World report on disability. Geneva: World Health Organization; 2011.

8. Bengel J, Koch U. Grundlagen der Rehabilitationswissenschaften: Themen, Strategien und Methoden der Rehabilitationsforschung. Berlin: Springer; 2000.

9. Gerdes N, Zwingmann C, Jäckel WH. The system of rehabilitation Germany. In: Jäckel WH, Bengel J, Herdt J, editors. Research in rehabilitation. Stuttgart: Schattauer; 2006. p. 3-19.

10. Advisory council on the assessment of developments in the health care system. Needs-based Health Care: Opportunities for Rural Regions and Selected Health Care Sectors, Report. Bonn: Advisory Council on the assessment of developments in the health care system; 2014.

11. Brzoska P, Voigtländer S, Spallek J, Razum O. Utilization and effectiveness of medical rehabilitation in foreign nationals residing in Germany. Eur J Epidemiol. 2010;25:651-60.

12. Meinlschmidt G. Gesundheitsberichterstattung Berlin. Basisbericht 2006/ 2007. Daten des Gesundheits- und Sozialwesens. Berlin: Senatsverwaltung für Gesundheit, Umwelt und Verbraucherschutz; 2007.

13. Maier C, Razum O, Schott T. Migration und rehabilitative Versorgung in Deutschland - Inanspruchnahme von Leistungen der medizinischen Rehabilitation und Rehabilitationserfolg bei Personen mit türkischem Migrationshintergrund. In: Muthny FA, Bermejo I, editors. Interkulturelle Medizin. Laientheorien, Psychosomatik und Migrationsfolgen. Köln: Deutscher Ärzte Verlag; 2008. p. 85-103.

14. Brzoska P, Razum O. Das Risiko einer Erwerbsminderung nach Abschluss der medizinischen Rehabilitation. Ein Vergleich von Rehabilitanden deutscher und ausländischer Staatsangehörigkeit im Längsschnitt. Präsentation auf der 7. Jahrestagung der Deutschen Gesellschaft für Epidemiologie, Regensburg, 26.-29. September, 2012. 2012.

15. Brause M, Reutin B, Razum O, Schott T. Rehabilitationserfolg bei Menschen mit türkischem Migrationshintergrund - Eine Auswertung von Routinedaten der Deutschen Rentenversicherungen Rheinland und Westfalen. Rehabilitation (Stuttg). 2012;51:282-8.

16. Sloots M, Scheppers E, Bartels EA, Dekker JH, Geertzen JH, Dekker J. First rehabilitation consultation in patients of non-native origin: factors that lead to tension in the patient-physician interaction. Disabil Rehabil. 2009;31: 1853-61.

17. Sloots M, Dekker JH, Pont M, Bartels EA, Geertzen JH, Dekker J. Reasons of drop-out from rehabilitation in patients of Turkish and Moroccan origin with chronic low back pain in The Netherlands: a qualitative study. J Rehabil Med. 2010;42:566-73.

18. Gary KW, Nicholls E, Shamburger A, Stevens LF, Arango-Lasprilla JC. Do racial and ethnic minority patients fare worse after SCI?: A critical review of the literature. NeuroRehabilitation. 2011:29:275-93.

19. Valencia $H$, Savage $P$, Ades PA. Cardiac rehabilitation participation in underserved populations. J Cardiopulm Rehabil Prev. 2011:31:203-10.

20. Friedly J, Akuthota V, Amtmann D, Patrick D. Why disability and rehabilitation specialists should lead the way in patient-reported outcomes. Arch Phys Med Rehabil. 2014;95:1419-22.

21. Fayers $P$, Machin D. Quality of life: the assessment, analysis and interpretation of patient-reported outcomes. Chichester: John Wiley \& Sons; 2013.

22. Mittag O, Raspe $\mathrm{H}$. Eine kurze Skala zur Messung der subjektiven Prognose der Erwerbstätigkeit: Ergebnisse einer Untersuchung an 4279 Mitgliedern der gesetzlichen Arbeiterrentenversicherung zu Reliabilität (GuttmanSkalierung) und Validität der Skala. Rehabilitation (Stuttg). 2003;42:174.

23. Ebinger M, Muche R, Osthus H, Schulte R-M, Gaus W, Jacobi E. Vorhersage der Erwerbsfähigkeit ein bis zwei Jahre nach einer stationären Rehabilitationsbehandlung bei Patienten mit Erkrankungen des Bewegungsapparates. Zeitschrift für Gesundheitswissenschaften. 2002;10:229-41.

24. Streibelt M. Einflussfaktoren auf den Erfolg stationärer orthopädischer Rehabilitation: Prädiktoren eines "Return to Work in good health". In: Deutsche Rentenversicherung Bund, editor. 15. Rehabilitationswissenschaftlichen Kolloquium. Tagungsband. Berlin: Deutsche Rentenversicherung Bund; 2006. p. 331-2.

25. Evangelou $E$, Tsianos $G$, loannidis JP. Doctorsâ $€^{T M}$ versus patientsâ $\epsilon^{\text {TM }}$ global assessments of treatment effectiveness: empirical survey of diverse treatments in clinical trials. BMJ. 2008:336:1287-90.

26. Elwyn G, Buetow S, Hibbard J, Wensing M. Respecting the subjective: quality measurement from the patient's perspective. Br Med J. 2007;335: $1021-2$.

27. Sullivan M. The new subjective medicine: taking the patient's point of view on health care and health. Soc Sci Med. 2003;56:1595-604. 
28. Hampel P, Graef T, Krohn-Grimberghe B, Tlach L. Effects of gender and cognitive-behavioral management of depressive symptoms on rehabilitation outcome among inpatient orthopedic patients with chronic low back pain: a 1 year longitudinal study. Eur Spine J. 2009;18:1867-80.

29. Meng K, Zdrahal-Urbanek J, Frank S, Holderied A, Vogel H. Patients' expectations, motivation and multi-dimensional subjective and objective socio-medical success in medical rehabilitation measures. Int J Rehabil Res. 2006;29:65-9.

30. Beutel ME, Bleichner F, von Heymann F, Tritt K, Hardt J. Inpatient psychosomatic treatment of anxiety disorders: Comorbidities, predictors, and outcomes. Int J Clin Health Psychol. 2011;11:443-57.

31. Moock J, Kohlmann T. Comparing preference-based quality-of-life measures: results from rehabilitation patients with musculoskeletal, cardiovascular, or psychosomatic disorders. Qual Life Res. 2008;17:485-95.

32. Farin $\mathrm{E}, \mathrm{Nagl} \mathrm{M}$. The patientâ€" physician relationship in patients with breast cancer: influence on changes in quality of life after rehabilitation. Qual Life Res. 2013:22:283-94.

33. Widera T, Grünbeck P. Rehabilitandenbefragung: Was hat die Adjustierung gebracht? Vortrag auf dem 19. Rehabilitationswissenschaftlichen Kolloquium. Leipzig, 8.-10. März. 2010.

34. Widera T. Ausblick zur Ergebnisqualität - Indikatoren einer erfolgreichen Rehabilitation sowie Einflussfaktoren auf das Rehabilitationsergebnis. In: Deutschen Rentenversicherung, editor. Ergebnisqualität in der medizinischen Rehabilitation der Rentenversicherung. Berlin: Deutschen Rentenversicherung; 2008. p. 168-95.

35. Gruner A, Oster J, Müller G, von Wietersheim J. Symptomatik, Krankheitsmodelle, Behandlungserleben und Effekte bei Patienten mit und ohne Migrationshintergrund in der psychosomatischen Rehabilitation. Z Psychosom Med Psychother. 2012;58:385-93.

36. Widera T. Aktuelles aus der Reha-Qualitätssicherung - neue Ergebnisse der Rehabilitandenbefragung. RVaktuell. 2010. 4/2010:153-9.

37. Deutsche Rentenversicherung. Handbuch zur Rehabilitandenbefragung. Befragung nach medizinischer Rehabilitation. Berlin: Deutsche Rentenversicherung Bund; 2012.

38. Dyar S, Lesperance M, Shannon R, Sloan J, Colon-Otero G. A nurse practitioner directed intervention improves the quality of life of patients with metastatic cancer: results of a randomized pilot study. J Palliat Med. 2012;15:890-5.

39. Shinga-Ishihara C, Nakai Y, Milgrom P, Murakami K, Matsumoto-Nakano M. Cross-cultural validity of a dietary questionnaire for studies of dental caries risk in Japanese. BMC Oral Health. 2014;14:1.

40. Boynton PM, Wood GW, Greenhalgh T. Hands-on guide to questionnaire research: reaching beyond the white middle classes. BMJ. 2004:328:1433

41. Rehfeld UG. Gesundheitsbedingte Frühberentung. Beiträge zur Gesundheitsberichterstattung des Bundes. Berlin: Robert Koch-Institut; 2006.

42. Tabachnick BG, Fidell LS. Using multivariate statistics. Boston: Pearson; 2010.

43. StataCorp. Stata Statistical Software: Release 12. College Station: StataCorp LP; 2011.

44. Borde T, David M, Kentenich $\mathrm{H}$. Erwartungen und Zufriedenheit deutsche und türkischsprachiger Patientinnen im Krankenhaus - eine vergleichende Befragung in einer Berliner Frauenklinik. Gesundheitswesen. 2002;64:476-85.

45. Brzoska P, Sauzet O, Yilmaz-Aslan Y, Widera T, Razum O. Die Zufriedenheit mit der medizinischen Rehabilitation bei Menschen mit Migrationshintergrund in Deutschland. Ergebnisse der Rehabilitandenbefragung der Deutschen Rentenversicherung. Präsentation auf dem 23. Rehabilitationswissenschaftlichen Kolloquium, Karlsruhe, 10.-12. März, 2014. 2014.

46. Bermejo I, Hölzel LP, Kriston L, Härter M. Subjektiv erlebte Barrieren von Personen mit Migrationshintergrund bei der Inanspruchnahme von Gesundheitsmaßnahmen. Bundesgesundheitsblatt - Gesundheitsforschung Gesundheitsschutz. 2012;55:944-53.

47. Yilmaz-Aslan Y, Brzoska P, Bluhm M, Aslan A, Razum O. Illness perceptions in Turkish migrants with diabetes: A qualitative study. Chronic IIIn. 2014;10: 107-21.

48. Brzoska P, Voigtländer S, Reutin B, Yilmaz-Aslan Y, Barz I, Starikow K, Reiss K, Dröge A, Hinz J, Exner A, et al. Rehabilitative Versorgung und gesundheitsbedingte Frühberentung von Personen mit Migrationshintergrund in Deutschland. Forschungsbericht 402. Berlin: Bundesministerium für Arbeit und Soziales; 2010.

49. Schwarz B, Starikow K, Salman R, Gutenbrunner C. Barrieren für MigrantInnen beim Zugang in die medizinische Rehabilitation. Karlsruhe:
Vortrag auf dem 23. Rehabilitationswissenschaftlichen Kolloquium; 2014. p $10-2$.

50. Haug S. Sprachliche Integration von Migranten in Deutschland. Working Paper 14. Reihe "Integrationsreport", Teil 2. Nürnberg: Bundesamt für Migration und Flüchtlinge; 2008.

51. Ackermann Rau S, Sakarya S, Abel T. When to see a doctor for common health problems: distribution patterns of functional health literacy across migrant populations in Switzerland. International Journal of Public Health; 2014, (10.1007/s00038-014-0583-5, online ahead of print).

52. Gracie B, Moon SS, Basham R. Inadequate health literacy among elderly immigrants: characteristics, contributing, and service utilization factorsBrownell Gracie, Sung Seek Moon, Randall Basham. J Hum Behav Soc Environ. 2012;22(7):875-95.

53. Berens E-M, Razum O. Einflussfaktoren auf die Teilnahme am Mammografiescreening-Programm bei Frauen mit türkischem Migrationshintergrund. Ergebnisse einer qualitativ-explorativen Studie Gesundheitsweisen. 2011:73:A179.

54. Kofahl C, von dem Knesebeck O, Hollmann J, Mnich E. Diabetesspezifsche Gesundheitskompetenz: Was wissen türkischstämmige Menschen mit Diabetes mellitus 2 über ihre Erkrankung? Gesundheitswesen. 2013;75:803-11.

55. Richter M, Schmidt-Ott G, Muthny F. Ziele, Zielerreichung und Patientenzufriedenheit in der psychosomatischen Rehabilitation. Z Psychosom Med Psychother. 2011;57:91-9.

56. George SZ, Hirsh AT. Distinguishing patient satisfaction with treatment delivery from treatment effect: a preliminary investigation of patient satisfaction with symptoms after physical therapy treatment of low back pain. Arch Phys Med Rehabil. 2005;86:1338-44.

57. Wickizer TM, Franklin G, Fulton-Kehoe D, Turner JA, Mootz R, Smith-Weller T Patient satisfaction, treatment experience, and disability outcomes in a population-based cohort of injured workers in Washington State: implications for quality improvement. Health Serv Res. 2004;39:727-48.

58. Babka von Gostomski C. Fortschritte der Integration Zur Situation der fünf größten in Deutschland lebenden Ausländergruppen. Nürnberg: Bundesamt für Migration und Flüchtlinge; 2010.

59. Brzoska P, Voigtländer S, Spallek J, Razum O. Die Nutzung von Routinedaten in der rehabilitationswissenschaftlichen Versorgungsforschung bei Menschen mit Migrationshintergrund: Möglichkeiten und Grenzen. Gesundheitswesen. 2012;74:371-8.

60. Voigtländer S, Brzoska P, Spallek J, Exner A, Razum O. Die Inanspruchnahme medizinischer Rehabilitation bei Menschen mit Migrationshintergrund. In: Schott T, Razum O, editors. Migration und gesundheitliche Ungleichheit in der Rehabilitation. Weinheim: Beltz Juventa; 2013. p. 92-104.

61. Aharony L, Strasser S. Patient satisfaction: what we know about and what we still need to explore. Med Care Rev. 1993;50:79.

62. Hasnain R, Kondratowicz DM, Borokhovski E, Nye C, Balcazar F, Portillo N, Hanz K, Johnson T, Gould R. Do cultural competency interventions work: a systematic review on improving rehabilitation outcomes for ethnically and linguistically diverse individuals with disabilities. FOCUS Tech Brief. 2011;31: $1-12$.

63. Côté D. Intercultural communication in health care: challenges and solutions in work rehabilitation practices and training: a comprehensive review. Disabil Rehabil. 2013;35:153-63.

64. Seeleman C, Essink-Bot ML, Stronks K, Ingleby D. How should health service organizations respond to diversity? A content analysis of six approaches. BMC Health Serv Res. 2015:15:510.

65. Razum O, Spallek J. Addressing health-related interventions to immigrants: migrant-specific or diversity-sensitive? Int J Public Health. 2014:59:893-5.

66. Gardenswartz L, Rowe A. Managing diversity. A complete desk reference and planning guide. New York: McGraw-Hill; 1998.

67. Kumra S, Manfredi S. Managing equality and diversity. Theory and practice. Oxford: Oxford University Press; 2012

68. Fleckman JM, Dal Corso M, Ramirez S, Begalieva M, Johnson CC. Intercultural competency in public health: a call for action to incorporate training into public health education. Frontiers in Public Health. 2015;3:210.

69. Gordin J. Diversity in Healthcare. In: Borowski N, editor. Organizational Behaviour in Health Care. Sudbury: Jones \& Bartlett; 2011. p. 15-40.

70. Weech-Maldonado R, Dreachslin JL, Dansky KH, De Souza G, Gatto M. Racial/ethnic diversity management and cultural competency: the case of Pennsylvania hospitals. J Healthc Manag. 2002;47:111-26. 